\title{
Interannual Variability of the Wind-Wave Regime Parameters in the Black Sea
}

\author{
B. V. Divinsky ${ }^{1, *}$, A. A. Kubryakov², R. D. Kosyan ${ }^{1}$ \\ ${ }^{1}$ Shirshov Institute of Oceanology, Russian Academy of Sciences, Moscow, Russia \\ ${ }^{2}$ Marine Hydrophysical Institute of RAS, Sevastopol, Russia \\ *divin@ocean.ru
}

\begin{abstract}
Purpose. The paper is aimed at studying climatic trends in variability of the average annual and average monthly fields of significant wave heights of the mixed and wind seas, swell and the wind speeds in the Black Sea region.

Methods and Results. Based on the MIKE 21 SW numerical model, the significant wave heights' fields of the mixed and wind seas, and also swell were obtained for the period from 1979 to 2018. Long-term wind velocity changes were analyzed using the ERA-Interim reanalysis data for the same period. Linear climatic trends in the average annual and average monthly variability of the significant wave heights and the average wind speeds were evaluated by the statistical methods.

Conclusions. The main feature of climatic variability of the significant wave height fields in the Black Sea is the pronounced spatial heterogeneity. In the western part of the sea, decrease in storm activity is observed. The eastern part is characterized by increase of the average significant wave heights. Statistically significant positive trends in fluctuations of the significant wave heights are observed in the coastal area from the Crimea southeast coast to the Georgia coast. Over the past 40 years, swell waves have intensified near the Turkish coast (to the east of Sinop) and near the Kerch Strait. The largest increase of the average monthly heights of mixed waves is observed in the eastern part of the sea in March and amounts 0.5-0.6 cm/year. This corresponds to increase of the average wind speeds by $\sim 0.025 \mathrm{~m} / \mathrm{s} /$ year. In November, decrease of storm activity is observed in the western part of the sea that is expressed in diminution of the monthly average values of the significant wave heights by $0.8 \mathrm{~cm} /$ year. Decrease of the average annual wave heights by $\sim 0.08 \mathrm{~cm} /$ year is observed in the southwestern part of the Black Sea. On the contrary, the whole eastern part of the sea is subject to the increased storm activity accompanied by growth of the average annual wave heights in the fields of the mixed and wind seas by $0.10-0.15 \mathrm{~cm} /$ year. The above-mentioned features reflect climatic variability of the average wind speeds, which are characterized by wind weakening in the western part of the sea $(0.010-0.015 \mathrm{~m} / \mathrm{s} /$ year) and its amplification in the sea eastern part $(0.015-0.020 \mathrm{~m} / \mathrm{s} /$ year).
\end{abstract}

Keywords: mathematical modeling, model DHI MIKE 21 SW, wind seas, swell, climate, trends.

Acknowledgements: the problem was set within the framework of the RFBR project No. 18-0580035, experimental data were analyzed due to the RFBR financial support (projects No. 19-45230004 and 20-05-00009); mathematical modeling and calculations were carried out with support of the RFBR grants (projects No. 19-05-00041 and No. 19-45-230002). The results were analyzed within the framework of program No. 0149-2019-0014 and the RSF project No. 20-17-00060. Variability of wind characteristics was analyzed within the framework of state task No. 0555-20190001.

For citation: Divinsky, B.V., Kubryakov, A.A. and Kosyan, R.D., 2020. Interannual Variability of the Wind-Wave Regime Parameters in the Black Sea. Physical Oceanography, [e-journal] 27(4), pp. 337-351. doi:10.22449/1573-160X-2020-4-337-351

DOI: $10.22449 / 1573-160 \mathrm{X}-2020-4-337-351$

(C) B. V. Divinsky, A. A. Kubryakov, R. D. Kosyan, 2020

(C) Physical Oceanography, 2020

\section{Introduction}

Wind waves are one of the main factors that determine hydro- and lithodynamic processes in the coastal zone of the sea, the ecological state of coastal waters, including their recreational potential. Spatial fields of surface waves are ISSN 1573-160X PHYSICAL OCEANOGRAPHY VOL. 27 ISS. 4 (2020) 
formed as a result of the impact of atmospheric formations of different nature, intensity and scale. Despite its relative isolation and relatively small size, the Black Sea, is part of the global climate system. The very fact of the global climate system restructuring (in other words, climate change) is not disputed these days. At the same time, the mechanisms of transformations, as well as the presence (or absence) of trends in long-period fluctuations observed in a particular region, are the subjects of intensive research and discussion.

Modern and extremely effective method for studying wind waves is mathematical modeling. It is based on the numerical solution of the wave energy balance equation, which reflects the physical laws at the stages of initiation, transformation and decay of surface waves. In world practice, the following models are most widely used: WAM [1], WAVEWATCH [2], SWAN [3] and DHI MIKE 21 $S W$ [4]. The most important technical aspects of modeling are presented in details in [5]. Spectral wave models are successfully used to study wave processes in a wide range of spatio-temporal variability, and also serve as a reliable tool for operational forecast of wind waves. In this regard, the work is worth to be paid attention to [6]. It shows the SWAN spectral model adaptation stages to take into account the peculiarities of its functioning in the Black Sea Center of Marine Forecasts.

A variety of works is devoted to the study of the wave climate in the Black Sea (see, for example, [7-17]). They used various models of wind waves, certain initial fields of the surface wind and carried out numerical experiments with tuning parameters of the models. The list of works, of course, is much wider, but most of the studies are of a regional nature or the analysis is based on limited (in time) initial data.

Several works in which the variability of the parameters of wind waves for the climatic period of time for the entire Black Sea water area is studied, can be noted. In [18], an analysis of the spatial and temporal variability of the Black Sea wave climate for 1979-2015 was carried out. The main conclusion made by the authors is as follows: in recent years in the Black Sea, the wave energy redistribution along the directions of its propagation has been observed. In the western part of the sea, this redistribution is reflected in an increase in the share of northeastern waves and a decrease in the contribution of northwestern waves. In the eastern part, the contribution of wind waves from the southeastern points increases with a weakening of the waves of the northwestern direction.

The article [19] analyzes the data for 1979-2009 and presents maps of the spatial distributions of monthly average indicators, as well as the coefficients of wind wave power variation. Analysis of the trend components was carried out for nine points selected along the Black Sea coast, while no statistically significant climatic trends were found. The article [20] is devoted to the study of the wave climate of the western Black Sea. Its author comes to a similar conclusion: no significant trends are observed in the fluctuations in the power of wind waves (at least for the region under study).

The article [21] presents the results of studies of the spatial variability of longperiod fluctuations of the main parameters of wind waves in the Black Sea, namely, mean significant wave heights and characteristics of extreme waves, which are $95 \%$ quantiles of distributions of significant heights. The main conclusion made 
in the article: the mean annual indicators of significant wave heights increase in the eastern Black Sea (up to $1.6 \%$ per year), while in the western part there is a negative trend (up to $-1.2 \%$ per year). It was also noted that in cases of strong and extreme disturbance, the estimates of linear trends are even greater.

The work [22] studies the climatic variability of wave energy flows in the southern and southwestern Black Sea. It is concluded that for all control points there is a decrease in the mean and an increase in the maximum wave power.

The result of work [23] was an analysis of the climatic fields of wind seas and swell power throughout the Black Sea for 1979-2018. It was found that there is a pronounced tendency to an increase in the mean wave power: for wind seas - in the northeastern and partly central parts of the sea; for the swell - in the east. In the field of mixed waves, an increase in the mean thickness is observed in the northeastern part of the sea. In the western part, there are no obvious tendencies in fluctuations in the mean wave power.

It can be concluded that now there is no unified understanding of climatic trends in fluctuations in the parameters of wind waves in the Black Sea.

The present work is aimed to carry out additional studies of climatic fluctuations in the parameters of surface waves and wind in the Black Sea and to identify possible trend components.

Note also that, as a rule, the following two main components are distinguished in the structure of real surface waves: wind seas, directly related to the local wind field, and swell waves propagating outside the wave generation zones (or moving with a phase velocity exceeding the wind speed). In other words, the energy spectrum of sea waves is formed as a result of the interaction of several wave systems. In this case, it is of interest to obtain separate wave characteristics for each of the wave components. It should also be noted that in contrast to the open ocean, where several different systems of swell waves may be present simultaneously, the characteristics of swell in the Black Sea are due to the limited geographic size and closeness of the sea area. For this reason, there is no the task of particularized detailing and in the concept of "swell" all surface waves are included, the direction of propagation of which does not agree with the general wind direction.

The main tasks of the research are defined as follows:

- to obtain climatic fields of significant heights of waves of mixed waves, wind seas and swell throughout the Black Sea for 1979-2018;

- to determine possible trends in climatic fluctuations of significant heights of wind, swell and mixed waves;

- to estimate values of climatic trends in fluctuations in the mean wind speeds in the Black Sea.

The main research method is mathematical modeling.

\section{The model description}

In the present work, the MIKE 21 SW spectral wave model of the Danish Hydraulic Institute (DHI) [4] is used. The model implements the main physical mechanisms of the generation, transformation and attenuation of wind waves, including the initial growth of waves under the effect of the surface wind, nonlinear intra-wave interactions, dissipation of wave energy due to whitecapping, bottom PHYSICAL OCEANOGRAPHY VOL. 27 ISS. 4 (2020) 
friction and collapse, refraction and diffraction of the wave field, interaction of surface waves and currents.

The calculation grid covers the entire Black and Azov Sea water area, consisting of 20,000 calculation elements (Fig. 1).

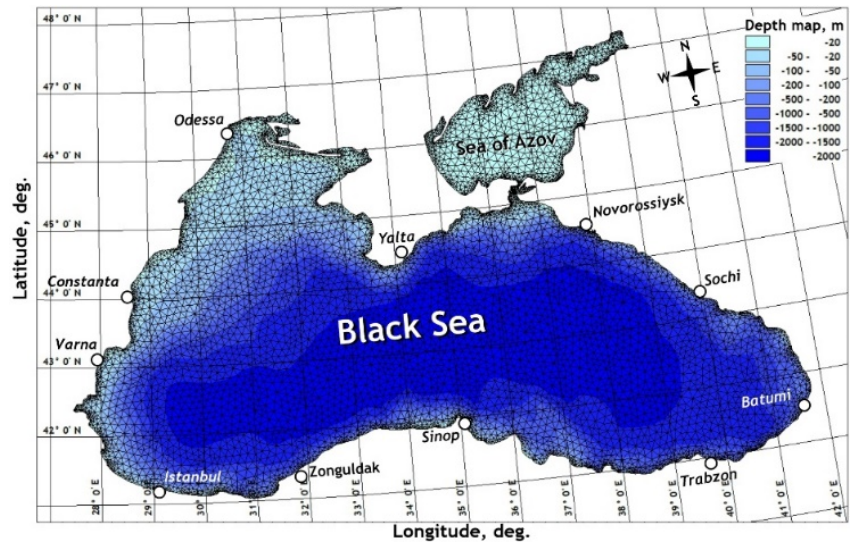

F i g. 1. Calculation grid and bathymetric map of the Black and Azov seas

The main morphological features of the Black Sea are presented below. Most of the sea is occupied by a deep-water basin with maximum depths over $2000 \mathrm{~m}$. Its northwestern part has a wide shelf strip up to $200 \mathrm{~km}$ long. The steep continental slope and shelf, not exceeding $20 \mathrm{~km}$, is characteristic of the southern and eastern coasts.

Despite that the shallow Azov Sea is included in the general computational grid, the results obtained for it are not entirely correct, since the sea area, as a rule, from November to March is characterized by the presence of an ice cover. Taking this circumstance into account will be the subject of further research.

The spectral model is optimized for the problem of separating the components of surface waves into wind seas and swell.

The main characteristics of the model are as follows:

- 50 spectral frequencies are distributed in the range of periods from 1.6 to $17.3 \mathrm{~s}$, using the relation $f_{n}=f_{0} C^{n}\left(f_{0}=0.055 \mathrm{~Hz}, C=1.05, n==1,2, \ldots 50\right)$;

- the number of discrete directions is 32, i.e., the resolution of the model in directions is $11.25^{\circ}$;

- separation of the wave components is carried out using the criterion that takes into account the "age" of the waves.

The MIKE 21 SW model was tuned using the results of various field studies carried out throughout the Black and Azov seas in a wide range of depths and wave formation conditions. To verify the model, data from experiments carried out using Datawell Waverider wave recorders, string wave recorders installed on stationary offshore platforms, ADCP instruments, as well as satellite measurements (altimetry) were used. The results of model verification are given in [18, 24].

The data of the global atmospheric reanalysis ERA-Interim provided by the European Center for Medium-Range Forecasts (URL: http://apps.ecmwf.int) are used as the initial wind fields. The studied area is limited by coordinates: $400^{\circ}$ 340

PHYSICAL OCEANOGRAPHY VOL. 27 ISS. 4 (2020) 
and $470^{\circ} \mathrm{N}$ in latitude, $270^{\circ}$ and $420^{\circ} \mathrm{W}$ in longitude. The spatial resolution of the wind fields is the same in latitude and longitude and is 0.250, the time step is 3 hours. ERA-Interim data for the Black Sea was verified in [25] based on comparison with contact measurements on the Golitsyno-4 gas platform.

\section{Results}

The works carried out resulted in the data array obtaining. It consists of fields of surface wave parameters in the Black Sea with a time step of 1 hour, covering a period of 40 years (1979-2018). Fields of significant heights of wind seas, swell and mixed excitement, being of interest, are selected from the general array

Analysis of possible trend components in the interannual fluctuations of the spatial fields of significant wave heights was carried out according to the technique described in detail in [26].

This procedure implements the nonparametric Mann-Kendall test. The method advantage is that it does not require knowledge of the distribution law of the initial values and can take into account the unevenness of the time scale and gaps in the available data.

The method considers three main statistical estimates:

- the Mann-Kendall statistics (S) (is the sum of differences between successive values),

- confidence factor $(C F)$,

- coefficient of variation (COV).

Combination of these three metrics permits to identify trend components in the initial data, as well as to assess the sign and statistical significance of trends. Interpretation of the results is a probabilistic assessment of a positive (negative) trend in the fluctuations of the studied parameter:

- increase ( $S>0$ and $C F>95 \%)$,

- $\quad$ probable increase $(S>0$ and $90 \%<C F<95 \%)$,

- $\quad$ no trend $((S>0$ and $C F<90 \%)$ or $(S \leq 0$ and $C F<90 \%$ and $C O V \geq 1)$ ),

- stable $(S \leq 0$ and $C F<90 \%$ and $C O V<1)$,

- probable decrease $(S<090 \%<C F<95 \%)$,

- decrease ( $S<0$ and $C F>95 \%)$.

The terms "no trend" and "stable" are copyrighted from [26]. To develop uniform estimate criteria, it is necessary to take certain fixed values of the $S$ and $C F$ parameters. However, there are situations in which the value of the studied parameter is very close to the boundary value; at the same time, the general analysis (including the visual one) in ambiguous cases permits to catch the general trend. For this reason, the estimation expressed by the formulation "no trend" will be referred to the "weak positive trend" category and "stable" - to the "weak negative trend" category.

To smooth the effect of possible random errors, the initial data were preliminarily averaged over spatial coordinates, and a rectangular grid with sides approximately equal to $40 \mathrm{~km}$ was formed. The procedure for transforming a triangulation grid into a rectangular one was carried out by linear interpolation methods using the internal DHI MIKE module.

Results of the analysis of possible trends in the fluctuations of mean annual and monthly average significant wave heights for mixed waves, as well as two of its components (wind seas and swell) are shown in Fig. 2 and 3 respectively. 


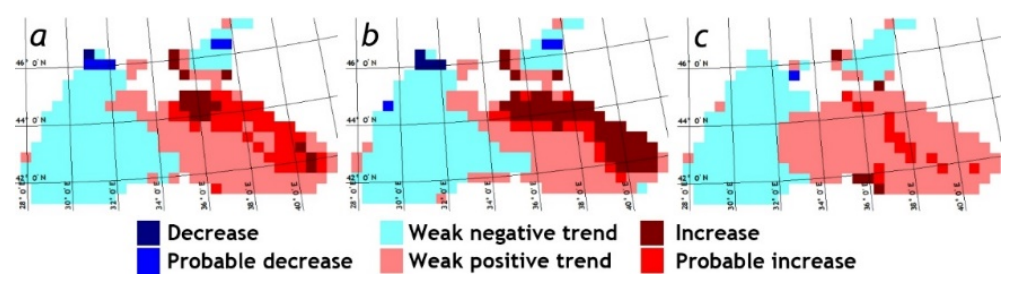

F i g. 2. Probabilistic assessment of linear trends of the average annual significant wave heights of mixed waves $(a)$, wind seas $(b)$ and swell $(c)$



F i g. 3. Probabilistic assessment of linear trends in fluctuations of the monthly average significant wave heights of mixed waves $(a)$, wind seas $(b)$ and swell $(c)$ 
According to Fig. 2, the main feature of the climatic variability of the average annual fields of significant wave heights in the Black Sea is a pronounced spatial or, more precisely, zonal heterogeneity.

Certain decrease in storm activity is observed in the western part of the sea. The eastern part is characterized by an increase in the average annual significant wave heights. Statistically significant positive trends in fluctuations of significant wave heights are observed in a wide coastal strip from the southeastern coast of Crimea to the coast of Georgia. This increase is most noticeable in the field of wind seas; for mixed waves, the increase is interpreted as probable. Over the past 40 years, swell waves intensified in the area of the Turkish coast to the east of Sinop and in the sea area adjacent to the Kerch Strait. The Azov Sea (its southern part) is characterized by a climatic growth of significant wave heights, but, as already mentioned, this conclusion can be attributed to an estimate.

The final picture of trends in climatic fluctuations, shown in Fig. 2, form intraseasonal fluctuations with their own pronounced features (Fig. 3).

According to Fig. 3, the wave climate shows relative stability in January, February and June. During these months, insignificant negative and positive trends in the fields of wind and mixed waves are recorded throughout the Black Sea. The exception is the swell, which intensifies in February in the northern part of the sea.

The following statistically significant trends in the monthly average fluctuations of significant wave heights are shown below:

- the positive ones - in March (western part of the sea), August (eastern), September (eastern and central) and October (central and southeastern);

- the negative ones - in May (eastern and central parts), July (south-eastern), November (eastern) and December (south-western and central).

Thus, there is a general decrease in storm activity in the winter months and its growth in the spring and autumn. Comparing Fig. 2 and 3, it can be seen that the distribution of average annual trends most closely matches the pattern of features of average monthly trends in March.

In absolute terms, the values of monthly average trends in fluctuations of significant heights of mixed waves (in $\mathrm{cm} /$ year) are shown in Fig. 4. For comparison, Fig. 5 shows the values of trends in fluctuations in average wind speeds over the Black Sea (in $\mathrm{m} / \mathrm{s} /$ year).

As follows from Fig. 4, 5 (quite expectedly), the spatial features of climatic fluctuations in wind parameters and surface waves almost coincide. The greatest increase in wave heights is observed in March in the eastern part of the sea and is $0.5-0.6 \mathrm{~cm} /$ year. This corresponds to an increase in average wind speeds by $\sim 0.025$ $\mathrm{m} / \mathrm{s} /$ year. In November, a decrease in storm activity is observed in the western part of the sea, reflected in a decrease in the average values of significant wave heights by $0.8 \mathrm{~cm} /$ year. This drop (for the western part) is so noticeable that it is not compensated by the average increase in wave heights in August-September.

Estimates of interannual values of trend components in fluctuations of significant heights of mixed waves, its components, as well as average wind speeds are shown in Fig. 6. Recall that the estimates are based on the data set for 1979-2018. 

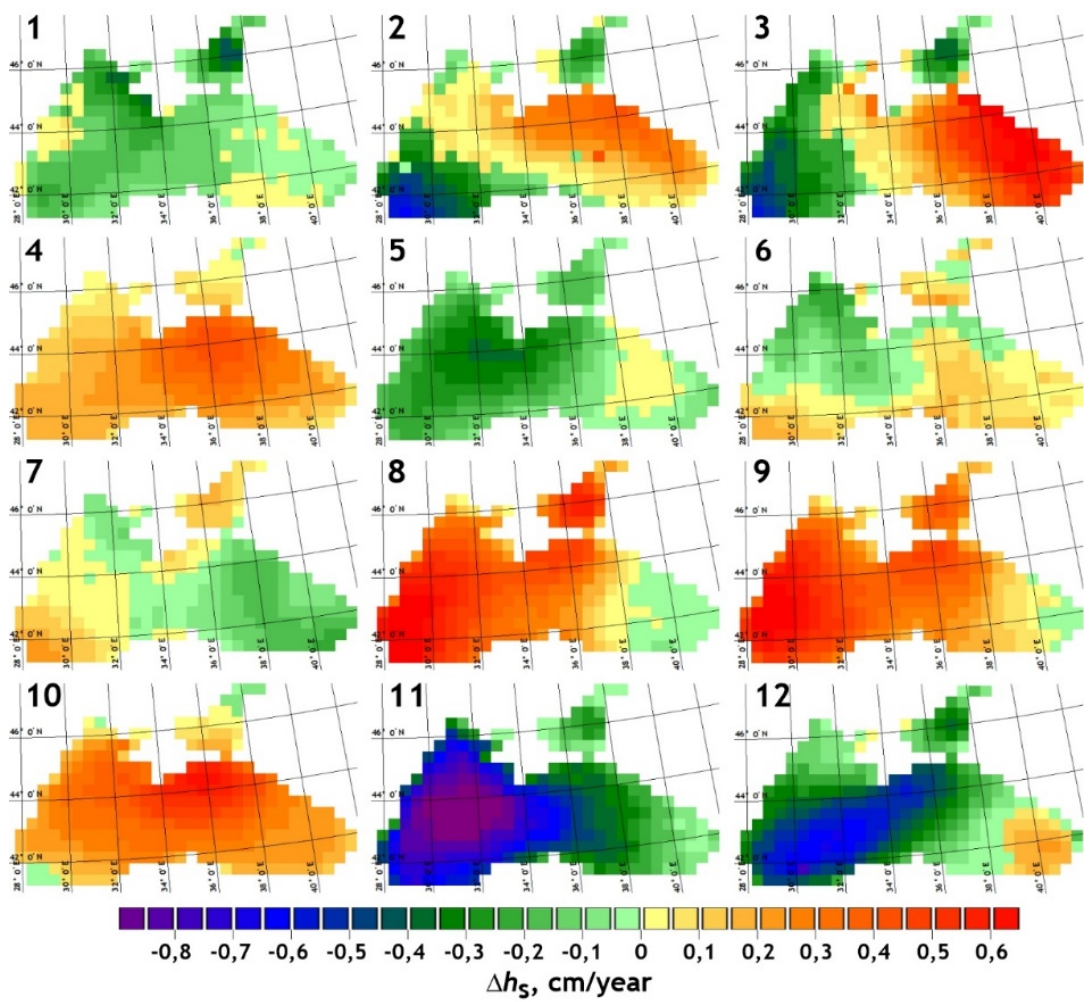

F i g. 4. Spatial distributions of the monthly average trends' values ( $\mathrm{cm} /$ year) in the significant wave height fluctuations of mixed waves
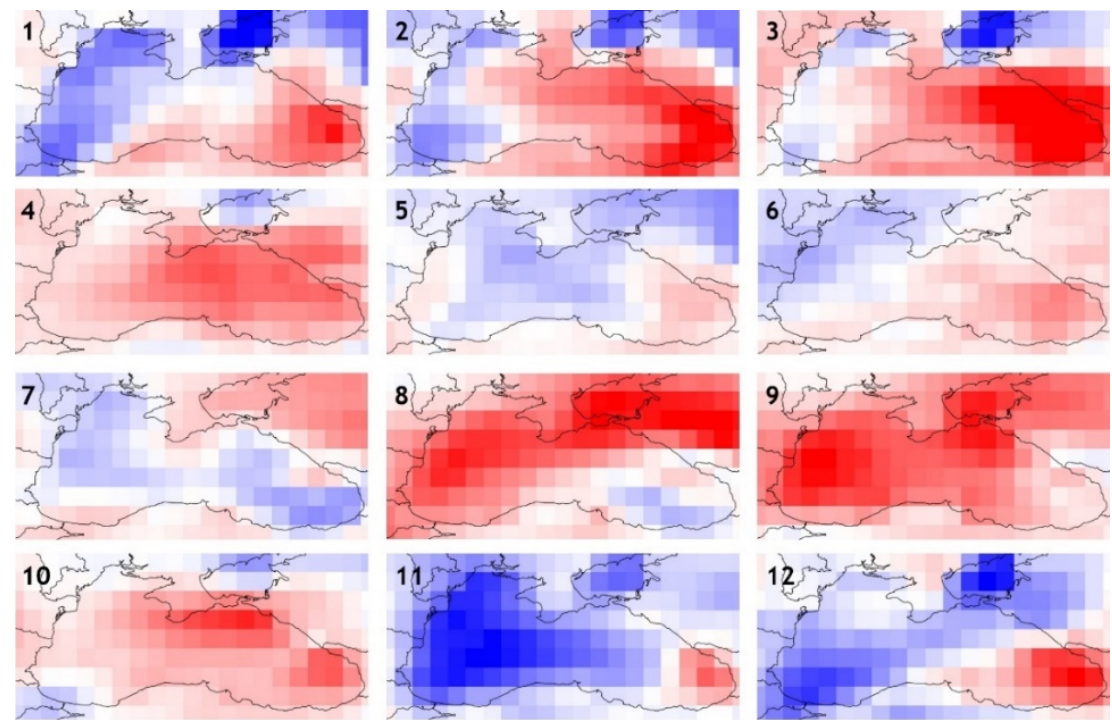

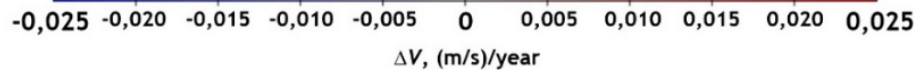

F i g. 5. Spatial distributions of the monthly average trends' values ( $\mathrm{m} / \mathrm{s} / \mathrm{year})$ in the average wind speed fluctuations 

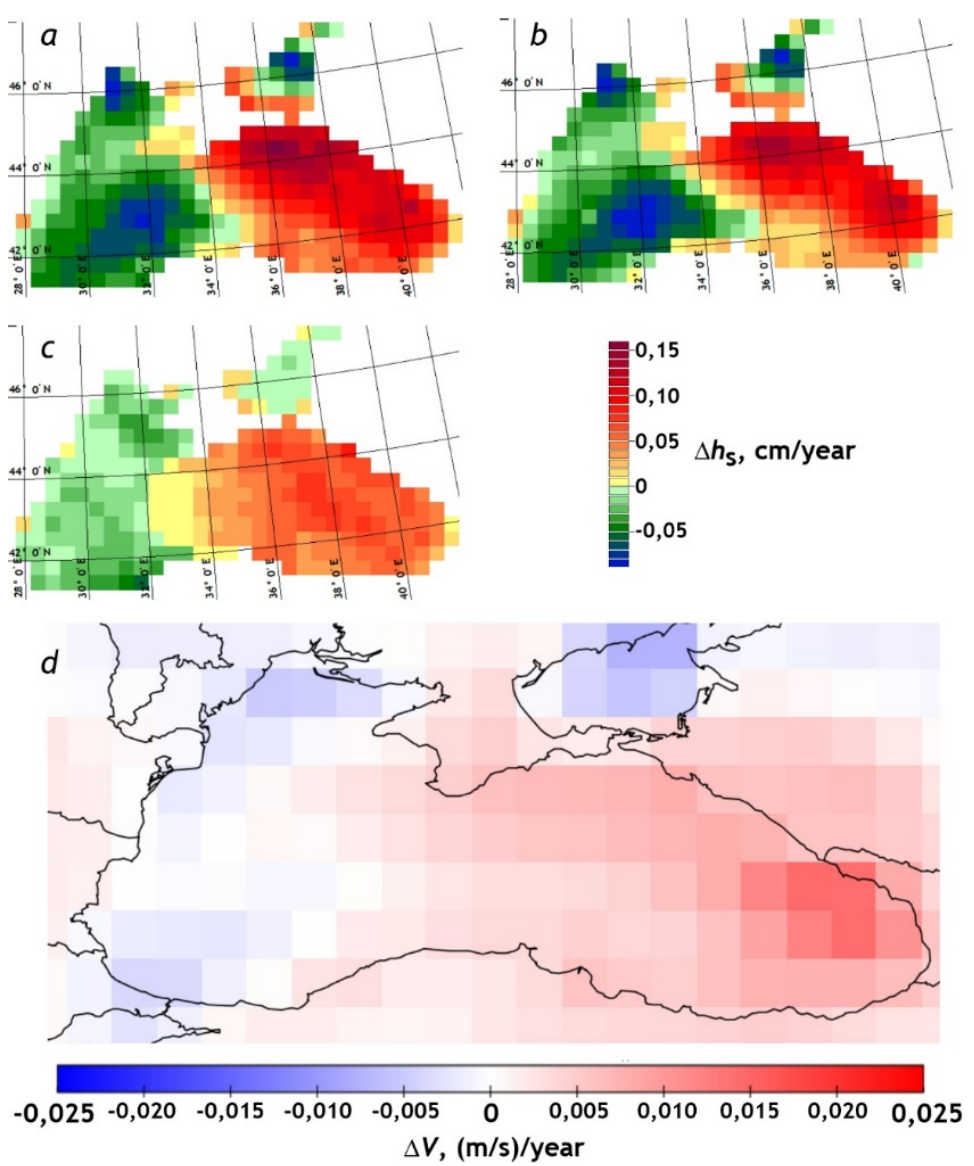

F i g. 6. Spatial distributions of the average annual trends' values in fluctuations of the significant wave heights of mixed waves $(a)$, wind seas $(b)$, swell $(c)$, and the average wind speeds $(d)$

As follows from Fig. 6, over the past 40 years, a pronounced redistribution of wave energy has been observed in the Black Sea. Despite the fact that the southwestern part of the sea is still the most turbulent, there is a decrease in the average annual heights of waves with speeds of about $0.08 \mathrm{~cm} /$ year. The entire eastern part is subject to increased storm activity with an increase in mean annual wave heights in the fields of mixed and wind seas by $0.10-0.15 \mathrm{~cm} /$ year. A similar picture is observed in the distribution of trend values for swell waves: in the western part, there is a decrease in swell heights by $\sim 0.05 \mathrm{~cm} /$ year, in the central and eastern regions - an increase by a number of the same order of magnitude. These features reflect the climatic fluctuations in average wind speeds (see Fig. 4, $d$ ), characterized by a wind weakening in the western part of the sea $(0.010-0.015 \mathrm{~m} / \mathrm{s} /$ year $)$ and an increase in the eastern part $(0.015-0.020 \mathrm{~m} / \mathrm{s} /$ year $)$.

Necessary notation. Strictly speaking, the analysis of the significance of linear climatic trends shown in Fig. 2, permits to speak of a significant increase in the average annual wave heights in the eastern part of the sea. The decrease in the average annual significant wave heights in the western part, so to speak, is pronounced, but lacks statistical significance. The picture shown in Fig. 2, is final 
and smoothed. If the individual seasons (months) are considered, it's found that storm activity decreases with the necessary reliability in the winter months, and increases in March and early autumn.

The obtained characteristics of the trends are quite well traced on the graph of the average annual variability of the significant wave height and wind speed, averaged over the western $\left(27.5^{\circ}-34.0^{\circ} \mathrm{E}\right)$ and eastern parts $\left(34^{\circ}-42^{\circ} \mathrm{E}\right)$ of the basin (Fig. 7).

The wave height variation curve corresponds to the variability of the main wave-generating factor - the wind. An increase in wave heights and wind speeds in the eastern part of the sea and a slight drop in the western part of the sea are clearly visible.

Similar features, namely, an increase in the wind speed in the eastern part of the basin and its decrease in the western one, were obtained in [27] based on scatterometer measurements for 2000-2017. In this work, such changes are associated with the long-term intensification and displacement of the Siberian anticyclone to the west towards the European part of Russia. Such a transformation of the global circulation leads to a change in the direction of the dominant winds from the northeast to the north in the eastern part of the basin and weakening the influence of the Azores maximum in the west of the sea. At the same time, the observed weakening of the northeastern winds, which determine the acceleration of waves in the northwestern part of the sea, as well as the northwestern winds associated with the action of the Azores anticyclone, leads to a decrease in wind energy in the western part of the sea [27]. A long-period decrease in wind speed and wave height in the western part of the sea is also recorded from the data of contact measurements. For example, in [28, 29], a negative trend in the wind speed in the northwestern part of the sea for 19452005 was found.

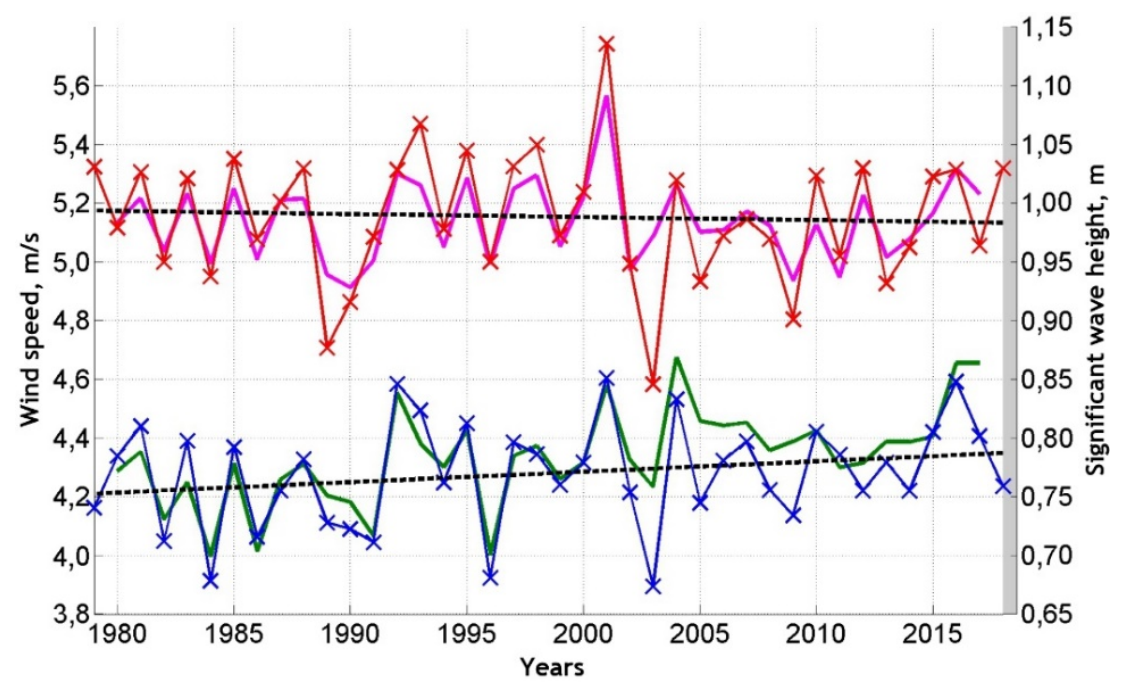

F i g. 7. Variability of the average annual values of the significant wave heights (m) in the western (red line) and eastern (blue line) parts of the sea and their approximation by the linear function (black lines); variability of the average annual wind speeds' values $(\mathrm{m} / \mathrm{s})$ in the western (purple line) and eastern (green line) parts of the sea 
The results of studies presented in [30] are in good agreement with these features. In the present article, based on the data of numerical reanalysis of atmospheric fields with an increased spatial resolution, it was concluded that the wind and vorticity fields differ significantly for the western and eastern halves of the sea.

Note also the significant interannual variability of the averaged wind-wave parameters (Fig. 7). The lowest wind and wave speeds in the western part of the sea were recorded in 1989 and 2003. The most significant waves and high wind speeds were recorded in 2001, characterized by anomalous phenomena in the marine ecosystem. In particular, the intensification of storms in 2001 caused a significant increase in the depth of the upper quasi-uniform layer of the sea [31] and the appearance of anomalous phytoplankton blossom in the summer [32]. Significant interannual variability can cause differences in the reported trend estimates based on the literature data for different periods.

\section{Conclusions}

As a result of the work carried out, average annual and monthly average climatic fields of significant heights of mixed waves, its main components (wind seas and swell), as well as wind speeds for the entire Black Sea water area for 1979-2018 were obtained.

Main feature of the climatic variability of the average annual fields of significant wave heights in the Black Sea is a well-pronounced spatial heterogeneity. Some decrease in storm activity is observed in the western part of the sea. Its eastern part is characterized by an increase in the average annual significant wave heights. Statistically significant positive trends in fluctuations of significant wave heights are observed in a wide coastal strip from the southeastern coast of Crimea to the coast of Georgia. This increase is most noticeable in the field of wind waves. Over the past 40 years, swell waves have intensified in the area of the Turkish coast to the east of Sinop and in the sea area adjacent to the Kerch Strait.

Probabilistic estimates of linear trends in fluctuations of average monthly significant heights of waves of mixed waves, wind seas and swells show that positive statistically significant trends are typical for March (in the western part of the sea), August (in the eastern), September (in the eastern and central) and October (in the central and southeastern), the negative ones - for May (in the eastern and central parts), July (in the southeastern), November (in the eastern) and December (in the southwestern and central). Thus, there is a general decrease in storm activity in winter and its increase in the spring-autumn months.

In absolute terms, the greatest increase in the average monthly heights of mixed waves is observed in March in the eastern part of the sea and is 0.5$0.6 \mathrm{~cm} /$ year. This corresponds to an increase in average wind speeds by $\sim 0.025 \mathrm{~m} / \mathrm{s} /$ year. In November, a decrease in storm activity is observed in the western part of the sea. It is reflected in a decrease in the average monthly significant wave heights by $0.8 \mathrm{~cm} /$ year. 
A decrease in the average annual heights of waves with velocities of $\sim 0.08 \mathrm{~cm} /$ year is observed in the southwestern Black Sea. The entire eastern part of the sea is subject to increased storm activity with an increase in mean annual wave heights in the fields of mixed and wind seas by $0.10-0.15 \mathrm{~cm} / \mathrm{year}$. A similar picture is observed in the distribution of trend values for swell waves: in the western part, there is a decrease in swell heights by $\sim 0.05 \mathrm{~cm} /$ year, in the central and eastern regions - an increase by a number of the same order. These features are a reflection of climatic fluctuations in average wind speeds with a characteristic weakening of the wind in the western part of the sea $(0.010-0.015 \mathrm{~m} / \mathrm{s} /$ year) and an increase in the eastern part $(0.015-0.020 \mathrm{~m} / \mathrm{s} /$ year$)$.

\section{REFERENCES}

1. Group, T.W., 1988. The WAM Model - a Third Generation Ocean Wave Prediction Model. Journal of Physical Oceanography, 18(12), pp. 1775-1810. https://doi.org/10.1175/15200485(1988)018<1775:TWMTGO>2.0.CO;2

2. Tolman, H.L., 1991. A Third-Generation Model for Wind Waves on Slowly Varying, Unsteady, and Inhomogeneous Depths and Currents. Journal of Physical Oceanography, 21(6), pp. 782-797. https://doi.org/10.1175/1520-0485(1991)021<0782:ATGMFW>2.0.CO;2

3. Booij, N., Ris, R.C. and Holthuijsen, L.H., 1999. A Third-Generation Wave Model for Coastal Regions: 1. Model Description and Validation. Journal of Geophysical Research: Oceans, 104(C4), pp. 7649-7666. https://doi.org/10.1029/98JC02622

4. DHI, 2007. MIKE 21 Wave Modelling. MIKE 21 Spectral Waves FM: Short Description. Horsholm: DHI, 14 p. Accessed at: https://www.mikepoweredbydhi.com//media/shared\%20content/mike\%20by\%20dhi/flyers\%20and\%20pdf/productdocumentation/short\%20descriptions/mike21_sw_fm_short_description.pdf [Accessed: 03 July 2020].

5. Cavaleri, L., Alves, J.-H.G.M., Ardhuin, F., Babanin, A., Banner, M., Belibassakis, K., Benoit, M., Donelan, M., Groeneweg, J., Herbers, T.H.C., Janssen, P.A.E.M., Janssen, T., Lavrenov, I.V., Magne, R., Monbaliu, J. [et al.], 2007. Wave Modelling - The State of the Art. Progress in Oceanography, 75(4), pp. 603-674. https://doi.org/10.1016/j.pocean.2007.05.005

6. Ratner, Yu.B., Fomin, V.V., Ivanchik, A.M. and Ivanchik, M.V., 2017. System of the Wind Wave Operational Forecast by the Black Sea Marine Forecast Center. Physical Oceanography, (5), pp. 51-59. doi:10.22449/1573-160X-2017-5-51-59

7. Saprykina, Y., Shtremel, M., Aydoğan, B. and Ayat, B., 2019. Variability of the Nearshore Wave Climate in the Eastern Part of the Black Sea. Pure and Applied Geophysics, 176(8), pp. 3757-3768. https://doi.org/10.1007/s00024-019-02143-1

8. Akpinar, A., and Ponce de León, S., 2016. An Assessment of the Wind Re-Analyses in the Modelling of an Extreme Sea State in the Black Sea. Dynamics of Atmospheres and Oceans, 73, pp. 61-75. https://doi.org/10.1016/j.dynatmoce.2015.12.002

9. Rusu, L., 2015. Assessment of the Wave Energy in the Black Sea Based on a 15-Year Hindcast with Data Assimilation. Energies, 8(9), pp. 10370-10388. https://doi.org/10.3390/en80910370 
10. Arkhipkin, V.S., Gippius, F.N., Koltermann, K.P. and Surkova, G.V., 2014. Wind Waves in the Black Sea: Results of a Hindcast Study. Natural Hazards and Earth System Sciences, 14(11), pp. 2883-2897. https://doi.org/10.5194/nhess-14-2883-2014

11. Akpinar, A., and Ihsan Kömürcü, M., 2013. Assessment of Wave Energy Resource of the Black Sea Based on 15-year Numerical Hindcast Data. Applied Energy, 101, pp. 502-512. https://doi.org/10.1016/j.apenergy.2012.06.005

12. Aydoğan, B., Ayat, B. and Yüksel, Y., 2013. Black Sea Wave Energy Atlas from 13 Years Hindcasted Wave Data. Renewable Energy, 57, pp. 436-447. https://doi.org/10.1016/j.renene.2013.01.047

13. Galabov, V., 2013. On the Wave Energy Potential of the Bulgarian Black Sea Coast. In: SGEM, 2013. 13th SGEM GeoConference on Water Resources. Forest, Marine and Ocean Ecosystems: SGEM2013 Conference Proceedings, June 16-22, 2013. Varna, Bulgaria, pp. 831-838. doi:10.5593/SGEM2013/BC3/S15.003

14. Myslenkov, S.A., Shestakova, A.A. and Toropov, P.A., 2016. Numerical Simulation of Storm Waves near the Northeastern Coast of the Black Sea. Russian Meteorology and Hydrology, 41(10), pp. 706-713. https://doi.org/10.3103/S106837391610006X

15. Polonsky, A.B., Fomin, V.V. and Garmashov, A.V., 2011. Characteristics of Wind Waves of the Black Sea. Reports of the National Academy of Sciences of Ukraine, (8), pp. 108-112 (in Russian).

16. Rusu, E., 2009. Wave Energy Assessments in the Black Sea. Journal of Marine Science and Technology, 14(3), pp. 359-372. https://doi.org/10.1007/s00773-009-0053-6

17. Cherneva, Z., Andreeva, N., Pilar, P., Valchev, N., Petrova, P. and Guedes Soares, C., 2008. Validation of the WAMC4 Wave Model for the Black Sea. Coastal Engineering, 55(11), pp. 881-893. https://doi.org/10.1016/j.coastaleng.2008.02.028

18. Divinsky, B.V. and Kosyan, R.D., 2017. Spatiotemporal Variability of the Black Sea Wave Climate in the Last 37 years. Continental Shelf Research, 136, pp. 1-19. https://doi.org/10.1016/j.csr.2017.01.008

19. Akpınar, A., Bingölbali, B. and Van Vledder, G.Ph., 2017. Long-Term Analysis of Wave Power Potential in the Black Sea, Based on 31-year SWAN Simulations. Ocean Engineering, 130, pp. 482-497. https://doi.org/10.1016/j.oceaneng.2016.12.023

20. Rusu, L., 2019. The Wave and Wind Power Potential in the Western Black Sea. Renewable Energy, 139, pp. 1146-1158. https://doi.org/10.1016/j.renene.2019.03.017

21. Aydoğan, B. and Ayat, B., 2018. Spatial Variability of Long-Term Trends of Significant Wave Heights in the Black Sea. Applied Ocean Research, 79, pp. 20-35. https://doi.org/10.1016/j.apor.2018.07.001

22. Akpınar, A., Jafali, H. and Rusu, E., 2019. Temporal Variation of the Wave Energy Flux in Hotspot Areas of the Black Sea. Sustainability, 11(3), 562. https://doi.org/10.3390/su11030562

23. Divinsky, B.V. and Kosyan, R.D., 2020. Climatic Trends in the Fluctuations of Wind Waves Power in the Black Sea. Estuarine, Coastal and Shelf Science, 235, 106577. https://doi.org/10.1016/j.ecss.2019.106577

24. Divinsky, B. and Kosyan, R., 2018. Parameters of Wind Seas and Swell in the Black Sea Based on Numerical Modeling. Oceanologia, 60(3), pp. 277-287. https://doi.org/10.1016/j.oceano.2017.11.006 
25. Garmashov, A.V., Kubryakov, A.A., Shokurov, M.V., Stanichny, S.V., Toloknov, Yu.N. and Korovushkin, A.I., 2016. Comparing Satellite and Meteorological Data on Wind Velocity over the Black Sea. Izvestiya, Atmospheric and Oceanic Physics, 52(3), pp. 309-316. https://doi.org/10.1134/S000143381603004X

26. Aziz, J.J., Ling, M., Rifai, H.S., Newell, C.N. and Gonzales, J.R., 2003. MAROS: A Decision Support System for Optimizing Monitoring Plans. Groundwater, 41(3), pp. 355-367. https://doi.org/10.1111/j.1745-6584.2003.tb02605.x

27. Kubryakov, A., Stanichny, S., Shokurov, M. and Garmashov, A., 2019. Wind Velocity and Wind Curl Variability over the Black Sea from QuikScat and ASCAT Satellite Measurements. Remote Sensing of Environment, 224, pp. 236-258. https://doi.org/10.1016/j.rse.2019.01.034

28. Repetin, L.N. and Belokopytov, V.N., 2008. Wind Climate of North-western Black Sea and Its Climatic Changes. In: MHI, 2008. Ekologicheskaya Bezopasnost' Pribrezhnykh i Shel'fovykh Zon i Kompleksnoe Ispol'zovanie Resursov Shel'fa [Ecological Safety of Coastal and Shelf Zones and Comprehensive Use of Shelf Resources]. Sevastopol: ECOSIGidrofizika. Iss. 17, pp. 225-243 (in Russian).

29. Ilyin, Yu.P., Repetin, L.N., Belokopytov, V.N., Goryachkin, Yu.N., D'yakov, N.N., Kubryakov, A.A., and Stanichny, S.V., 2012. [Hydrometeorological Conditions of the Ukrainian Seas. Vol. 2: The Black Sea]. Sevastopol, 421 p. (in Russian).

30. Efimov, V.V. and Anisimov, A.E., 2011. Climatic Parameters of Wind-Field Variability in the Black Sea Region: Numerical Reanalysis of Regional Atmospheric Circulation. Izvestiya, Atmospheric and Oceanic Physics, 47(3), pp. 350-361. https://doi.org/10.1134/S0001433811030030

31. Kubryakov, A.A., Belokopytov, V.N., Zatsepin, A.G., Stanichny, S.V. and Piotukh, V.B., 2019. The Black Sea Mixed Layer Depth Variability and Its Relation to the Basin Dynamics and Atmospheric Forcing. Physical Oceanography, 26(5), pp. 397-413. doi:10.22449/1573160X-2019-5-397-413

32. McQuatters-Gollop, A., Mee, L.D., Raitsos, D.E. and Shapiro, G.I., 2008. Non-Linearities, Regime Shifts and Recovery: The Recent Influence of Climate on Black Sea Chlorophyll. Journal of Marine Systems, 74(1-2), pp. 649-658. https://doi.org/10.1016/j.jmarsys.2008.06.002

About the authors:

Boris V. Divinsky, Leading Research Associate, P.P. Shirshov Institute of Oceanology RAS (36 Nakhimovsky Ave., Moscow, 117997, Russia), Ph. D. (Geogr.), ORCID ID: 0000-0002-24521922, ResearcherID: C-7262-2014, divin@ocean.ru

Arseniy A. Kubryakov, Senior Research Associate, Marine Hydrophysical Institute of RAS (2 Kapitanskaya St., Sevastopol, 299011, Russia), Ph. D. (Phys.-Math.), ORCID ID: 0000-0003-35615913, arskubr@mhiras.ru.

Ruben D. Kosyan, Head of the Laboratory of Geology and Lithodynamics, P.P. Shirshov Institute of Oceanology RAS (36 Nakhimovsky Ave., Moscow, 117997, Russia), Professor, ResearcherID: C-5154-2014, rkosyan@hotmail.com. 
Contribution of the co-authors:

Boris V. Divinsky - formulation of the goals and objectives of the study; analysis of materials on the research topic; correction of the mathematical model and carrying out calculations; processing and description of research results; preparation of the initial version of the text

Arseniy A. Kubryakov - formulation of the goals and objectives of the study; correction of the mathematical model and carrying out calculations; qualitative analysis of the results and their interpretation; processing and description of research results; preparation of the initial version of the text

Ruben D. Kosyan - initiation of research; general scientific management of research; analysis and generalization of research results; revision of the text

All the authors have read and approved the final manuscript.

The authors declare that they have no conflict of interest. 